\title{
Basalt Fiber on Cinder Strength of Lightweight Aggregate Concrete
}

\author{
Liguang Xiao, Qingshun Liu \& Jiheng Li
}

College of Material Science and Engineering, Jilin Jianzhu University, Changchun Province, China

Keywords: Fiber Concrete; Basalt Fiber; Fiber Reinforcement; Capability; Modified

Abstract. Lightweight aggregate concrete has a lot of excellent properties such as light weight, high strength, heat preservation, heat insulation, fire proof, antifreeze, earthquake, and is resistant to chemical cor-rosion. It is a high-rise buildings which has frame structure, large-span, soft soil foundation, and the durability of high ideal concrete materials used in civil engineering, but they will generate crack, brittle and poor tough-ness easily. This article adopts the method of fiber modification, basalt fiber is studied on the influence of cinder on the mechanical properties of lightweight aggregate concrete, the toughening mechanism was ana-lyzed and got the optimum content of basalt fiber, experiment prove that basalt fiber significantly improved the cinder light aggregate concrete flexural strength and toughness.

\section{Introduction}

Basalt fiber is a natural basalt ore as raw material, continuous fiber is made after high temperature melting. With carbon fiber, Synthetic fiber, such as polyethylene fiber, basalt fiber with acid and alkali resistance, low moisture absorption, and outstanding advantages such as good insulation, adiabatic, sound insulation performance. Gradually become a new material in the field of concrete enhancement.

At present, due to the exploitation of refining technology matures, basalt fiber from military defense applications start to construction in the concrete, and gradually become the focus of research both at home and abroad, such as Lian Jie and others studied the influence of basalt fiber volume content and the aspect ratio of the filament basalt fiber on concrete compressive strength, splitting tensile and breaking strength of basalt fiber concrete. As is shown that, adding chopped basalt fiber in concrete, strength and breaking resistance of concrete has been significantly improved. Dias D P, Thaumaturgo $\mathrm{C}$ and others studied the fracture toughness of basalt fiber concrete and mechanical properties of ordinary Portland concrete with basalt fiber reinforced. It shows that: when mixed with appropriate amount of basalt fiber, BFRC compressive strength and splitting tensile strength has reduced to varying degrees; and breaking strength improved significantly, and what can be seen from ultimate load beams test is that basalt incorporation extend the time of the beam failure. ${ }^{[1-4]}$

Light aggregate concrete has a lot of excellent properties, light weight, high strength, heat preservation, heat insulation, fireproof, antifreeze, earthquake, and is resistant to chemical corrosion. It is a high-rise buildings, frame structure, large-span, soft soil foundation, and is fit to the ideal concrete materials used in civil engineering. But light aggregate concrete is easy to generate craze, bigger brittleness. We are supposed to enhance toughness of lightweight aggregate concrete and find the key technologies of high performance lightweight aggregate concrete. This paper systematically studied the influence of basalt fiber on the mechanical behavior of cinder lightweight aggregate concrete. ${ }^{[5,6]}$

\section{The Experimental Process}

\subsection{Raw materials and their properties}

Cement: Jilin honored cement limited company. Production tripod deer card P.O 42.5 R ordinary Portland cement; Fly ash: meeting the national stan-dard of grade II. Super plasticizer: LCX - 9 poly carboxylic acid high efficiency water reducing agent, for index conforms to GB8076-1997 product homo-geneity. Basalt fiber: Jilin province Jiuxin basalt in-dustrial group co LTD, including $13 \mathrm{~mm}$ in diame-ter, length of $18 \mathrm{~mm}$. Main performances are shown in table 1, the experiment with 
basalt fiber is as shown apparently in figure 1; Cinder: Cinder surface showing honeycomb, is a kind of foamy vitreous rocks, apparent density is small, is a kind of natural light aggregate, Using the culvert building materials development limited company. Jilin province pro-vide Cinder, main performances are shown in table 2, microscopic structure is as shown in figure 2. Water: tap water.

Table 1 Basalt fiber physical and mechanical properties

\begin{tabular}{cccc}
\hline $\begin{array}{c}\text { Length } \\
(\mathrm{mm})\end{array}$ & $\begin{array}{c}\text { Diameter } \\
(\mu \mathrm{m})\end{array}$ & $\begin{array}{c}\text { Density } \\
(\mathrm{g} / \mathrm{cm})\end{array}$ & $\begin{array}{c}\text { Elasticity } \\
\text { modulus } \\
(\mathrm{Gpa})\end{array}$ \\
\hline $17-19$ & 13 & 2.61 & $78.2-94.1$ \\
\hline $\begin{array}{c}\text { Breaking } \\
\text { elongation } \\
(\%)\end{array}$ & $\begin{array}{c}\text { Temperature } \\
{ }^{\circ} \mathrm{C}\end{array}$ & $\begin{array}{c}\text { Water con- } \\
\text { tent }(\%)\end{array}$ & $\begin{array}{c}\text { Tensile } \\
\text { strength } \\
(\mathrm{Mpa})\end{array}$ \\
\hline 3.0 & $<650$ & $<4$ & $4150-4800$ \\
\hline \multicolumn{2}{c}{ Table 2. The performance parameters of cinder }
\end{tabular}

\begin{tabular}{ccccc}
\hline $\begin{array}{c}\text { Particle } \\
\text { Size } \\
(\mathrm{mm})\end{array}$ & $\begin{array}{c}\text { Bulk den- } \\
\text { sity } \\
(\mathrm{kg} / \mathrm{m} 3)\end{array}$ & $\begin{array}{c}\text { Cylinder } \\
\text { pressure } \\
\text { strength } \\
(\mathrm{MPa})\end{array}$ & $\begin{array}{c}\text { 1h water } \\
\text { absorption } \\
(\%)\end{array}$ & $\begin{array}{c}\text { Conductivi- } \\
\text { ty } \\
(\mathrm{W} / \mathrm{mK})\end{array}$ \\
\hline $0-8$ & 1 & 5 & 30.6 & 0.0802 \\
\hline
\end{tabular}

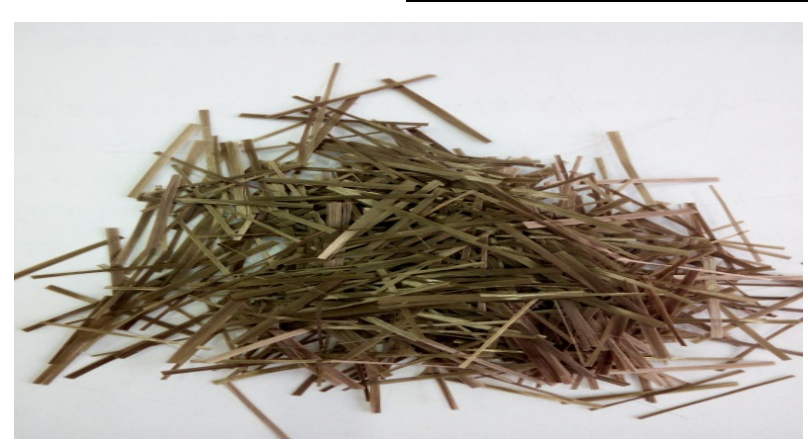

Figure 1 Basalt fiber

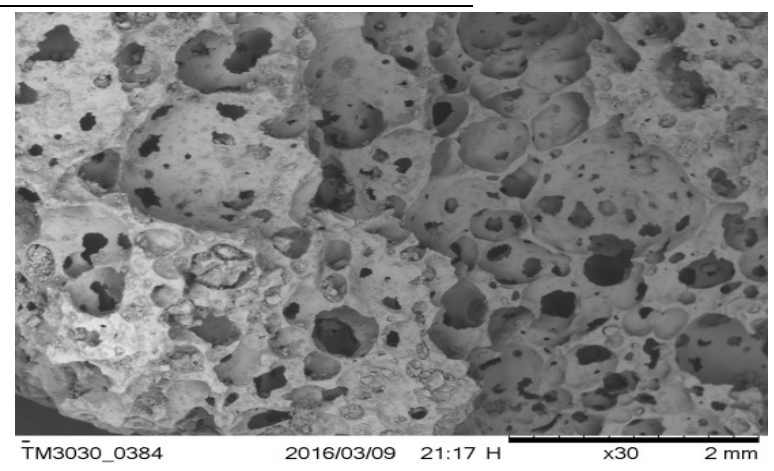

Figure 2 Cinder microscopic structure

\subsection{Experiment Procedures}

Tests are in accordance with the ordinary concrete mechanics performance test method standard GB/T50081-2002, such as the cinder light aggregate concrete compressive strength, flexural strength. Specific experimental processes are as follows: Compressive flexural strength test: through mixing cinder light aggregate concrete, and three minutes in pack mode, I put it into implementation to prepared $100 \mathrm{~mm} * 100 \mathrm{~mm} * 100 \mathrm{~mm}$ experimental mold, vibrating 25 after mold, molding, dismantle within 48h,28 days later, We use cement mortar (JR-KZ300DS) flexural compressive machine to test compressive strength, flexural strength; Finally using calculating pressure ratios show toughness of light aggregate concrete with cinder. scanning electron microscope (SEM) test: It will be part of the specimen random slice, grinding, dilute hydrochloric acid, with anhydrous ethanol to wash clean, dry and set aside. Under the condition of vacuum, the surface plating is observed by scanning electron microscope (SEM).

\section{Results And Discussion}

\subsection{The influence of basalt fiber on strength of lightweight aggregate concrete}

In order to explore the basalt fiber on the mechanical properties of lightweight aggregate concrete influence we the flexural and compressive strength were tested, macro diagram as shown in figure 3 , figure 4 . 


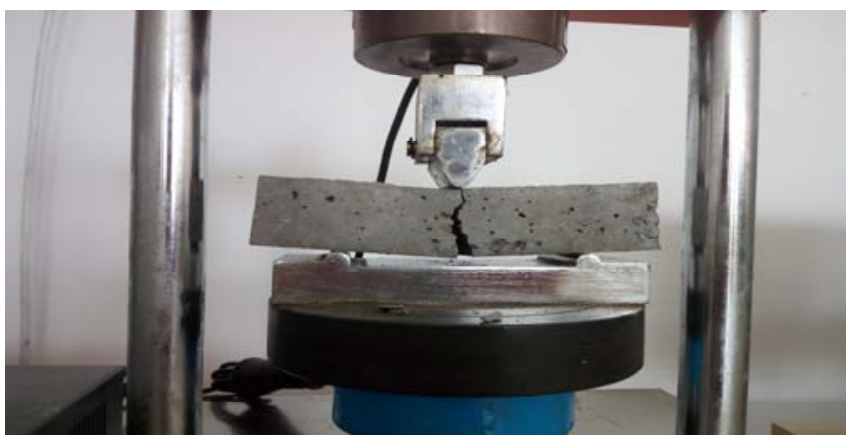

Figure 3 Without adding basalt fiber lightweight aggregate concrete

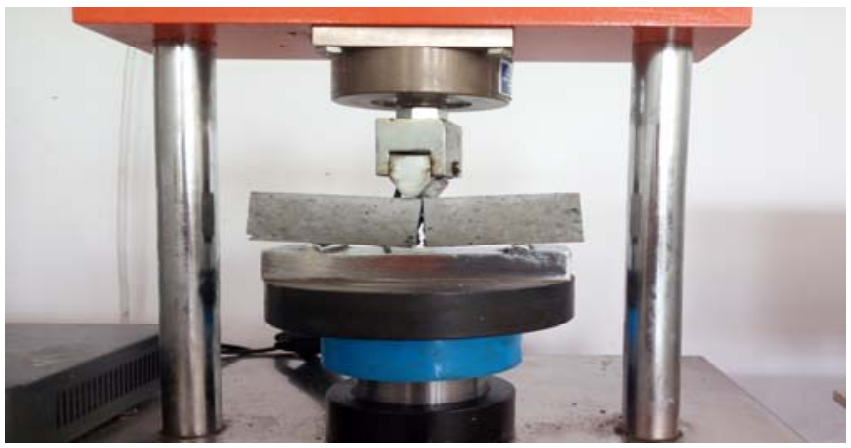

Figure 4 Basalt fiber reinforced concrete dosage was 0.3\%

As can be seen from the figure 3, without adding basalt fiber lightweight aggregate concrete in external load is vertical fracture cross section. And the dosage of $0.3 \%$ basalt fiber reinforced concrete with load is present and fracture in figure 4. This is due to Basalt fiber dispersed evenly in the lightweight aggregate concrete, Forming a mesh structure, In concrete are destroyed when the transfer of energy from the matrix, Through the stress redistribution, Will continue to the energy transfer to the cracks on both sides of the specimen.

Basalt fiber's influence on cinder light aggregate concrete flexural strength and compressive strength is shown in fig 5 -fig 6.

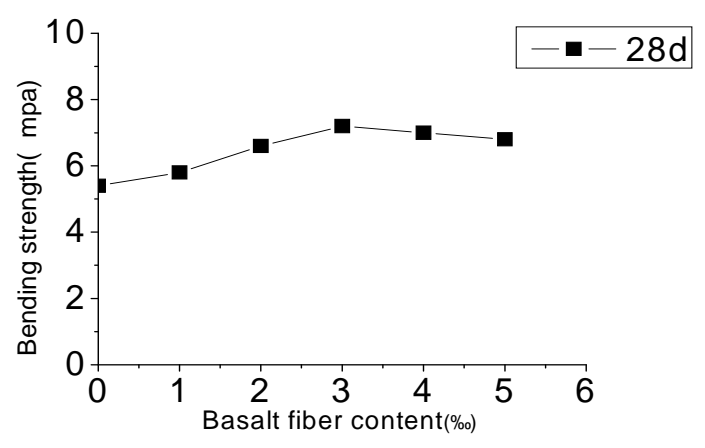

Figure 5 Basalt fiber on flexural strength of lightweight Figure 6 Basalt fiber on compressive strength of lightweight aggregate concrete

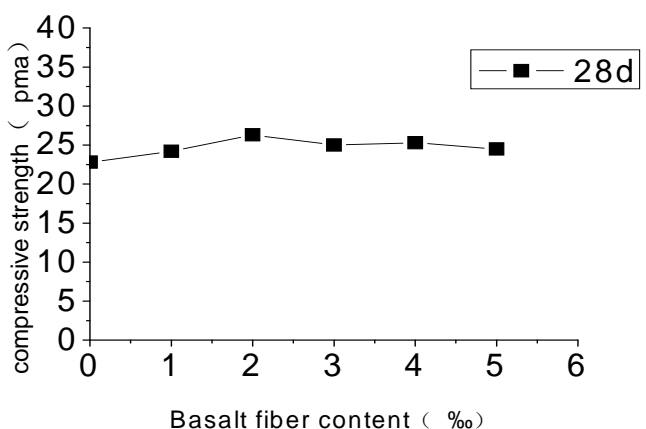

aggregate concrete

As can be seen from the figure 3 , figure 4 , When the basalt fiber concrete dosage is $1 \%$, the compressive strength of lightweight aggregate concrete have no obvious change, and the flexural strength improved; As content gradually increases, the compressive strength and flexural strength are on the rise. Basalt fiber dosage is $3 \%$, the flexural strength in a best point. Because of its high specific surface area of the basalt fiber, rough surface, high friction coefficient, it increased the mixing flow relative friction, block light aggregate buoyancy, the uniformity and workability of concrete; On the other hand, the basalt fiber has good hydrophilicity. After the basalt fiber mixed with mixture, then dispersed into thin flocculent silks, packaging the flocculent fiber requires a lot of cement mortar, which makes the mixture flow performance reduced. Basalt fiber dispersed evenly in the lightweight aggregate concrete, to form a mesh structure, The energy which is transmitted 
from the base body is damaged when the matrix is destroyed, thereby increasing the compressive strength and bending strength.

When the basalt fiber content exceeds 3\%o, compressive strength, flexural strength decreased. Because of basalt fiber with high water absorbability, absorbed water in the process of mixing cement hydration, concrete mixing at high caking phenomenon, because of the distribution, it formed more holes in the matrix, making a large number of defects around the interface, and then at the interface between fiber and cement presents a poor link performance. The strength of lightweight aggregate concrete is reduced.

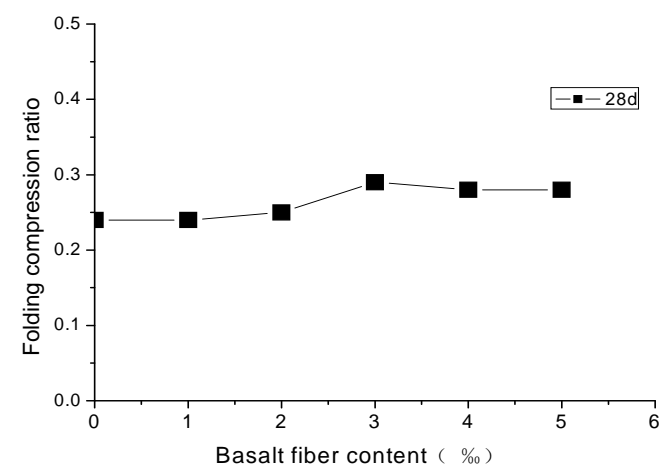

Figure 7 Basalt fiber's influence on the toughness of lightweight aggregate concrete

As can be seen from the figure 7, with the increase of dosage of basalt fiber, folding compression is higher than that of the corresponding pressure, we can learn from figure 5 and figure 6 , without destroying the compressive strength of concrete, its flexural strength has improved greatly, which improved the toughness of lightweight aggregate concrete. When the dosage of basalt fiber is $3 \%$, it perform best, compressive strength increased by $2 \%$, the flexural strength increased by $33.4 \%$, and not only the flexural strength and compressive strength, it significantly improved the toughness of lightweight aggregate concrete.

\subsection{Basalt fiber reinforced concrete microstructure and the toughening mechanism are analysis and discussed}

We use SEM to further verify the reason why basalt fiber increase the toughness of lightweight aggregate concrete, as is shown in figure 8
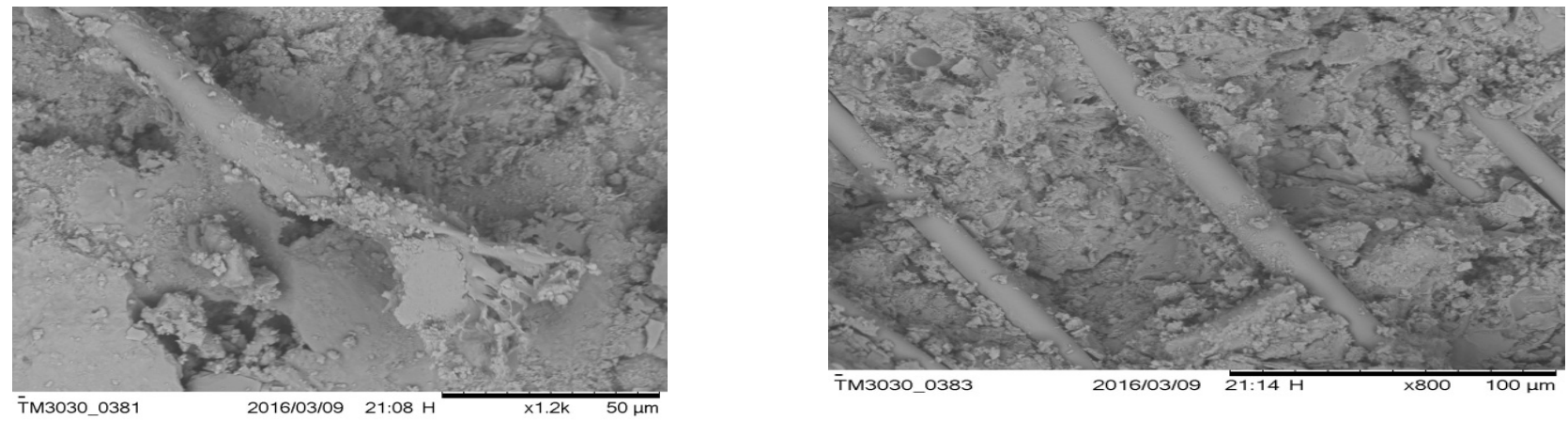

Figure 8 Basalt fiber modified light aggregate concrete microstructure

Between fiber and cement good coupling interface, there is little hole and porosity in the matrix. Basalt fiber combined with lots of cement on the surface. The basalt fiber belongs to the silicate series, so it can combine with cement strongly. Under loading, Fiber inside the concrete crack pull out from the cracking of cement matrix, to overcome the friction between the fiber and cement matrix interface consume a larger work. At the same time it need energy for stress passing from the matrix to the fiber. Basalt fiber mixed with the crack produce stress field, and reduces the degree of the crack tip stress concentration, fiber constraint the cracks' propagation, so as to effectively improve 
the mechanical performance of concrete. So, it can verify when the basalt fiber dosage is 3\%, it has the most satisfied performance, and increase the compressive strength and toughness of lightweight aggregate concrete significantly.

\section{Conclusions}

A technique of basalt fiber reinforce the cinder concrete mechanical properties and microstructure to get the following conclusion, After mixed with basalt fiber, light aggregate concrete's compressive strength and bending strength increased, and flexural strength increased significantly higher than the compressive strength, greatly improving the folding ratio of light aggregate concrete, which significantly improved the toughness of lightweight aggregate concrete. With basalt fiber content gradually increases, when the basalt fiber dosage is $3 \%$, the compressive strength increased by $2 \%$, the flexural strength increased by $33.4 \%$, the basalt fiber content into $3 \%$.

\section{References}

[1] Li-guang Xiao, Rong-Hua, Jin-hong Yin. 2010. Plant fiber affect the performance of Light aggregate concrete. Jilin Institute of Architectural Engineering 5:21-23

[2] Lan-fang Zhang, Yu-long Yin, Jing-wei Liu, Qiu-shuang Liang. 2014. Mechanical properties of basalt fiber reinforced concrete research. Bull Chin Ceram Soc 33:2834-2837.

[3] Lun-fang Huo, Jin-shuai Li. 2008. Fiber blend's influence on the mechanical properties of lightweight aggregate concrete . Journal of Inner Mongolia university of technology 1:59-64.

[4] Jing-jun Li. 2015. Model steel fiber reinforced lightweight aggregate concrete mechanical properties and microstructure test research . Inner Mongolia university of science and technology.

[5] Jiang-feng Dong, Qing-yuan Wang. 2012. The basic mechanical properties of basalt fiber recycled concrete. Journal of sichuan university S2:9-12.

[6] Bang-tu Ye, Jin-yang Jiang. 2013. Basalt fiber and its research progress of reinforced cement based materials. Materials review 12:102-108. 